\title{
Interpretación de vistas fotográficas como método de análisis del paisaje cultural. Transformaciones en el territorio minero de Lota, Chile ${ }^{1}$
}

\author{
María Isabel López Meza², Ignacio Bisbal ${ }^{3}$ y Leonel Pérez ${ }^{4}$
}

\begin{abstract}
RESUMEN
El estudio de las dinámicas del paisaje constituye un insumo clave para la gestión del paisaje patrimonial. El artículo presenta una propuesta metodológica basada en: a) la repetición de fotografías históricas, b) su procesamiento digital, c) la identificación de las isovistas o cuencas visuales en SIG, y d) la fotointerpretación del cambio en relación a las edificaciones, la infraestructura, la vegetación, los cuerpos de agua y el suelo. Identificadas estas categorías, se analizan los principales patrones de cambio acaecidos en Lota entre principios del siglo XX y principios del XXI con respecto a la categoría de suelo. Los resultados señalan la utilidad de la metodología en tanto que descubre lugares históricamente significativos y su alteración en el tiempo. En relación al caso analizado, los resultados indican que es en las antiguas áreas mineras y periurbanas donde se concentran las transformaciones más importantes; incluyendo alteraciones del relieve, relleno de antiguas bahías y ocupación urbana de los cerros.
\end{abstract}

Palabras clave: Patrimonio, minero, paisaje, fotografía repetida, dinámica de paisaje

\begin{abstract}
Analysis of landscape dynamics is a key input for managing historic areas. The article presents a methodological approach based on: a) re-capturing historical images, b) digital image processing, c) identification of view sheds in GIS, and d) photographic interpretation of landscape dynamics. Photographic interpretation is based on five categories of landscape elements: buildings, infrastructure, vegetation, bodies of water and land. Focusing on the last category, we identified the principal patterns of landscape transformation that took place in Lota between the beginning of the 20th and the beginning of the 21 st centuries. Results indicate the effectiveness of this method in identifying places that were significant in the past and their transformation through time. For Lota in particular, the results also indicate that the former mining and suburban areas have been the most altered. Changes include: modifications in relief, infilling of old bays and the urbanization of the hills.
\end{abstract}

Key words: heritage, mining, landscape, photography, repeat photography

1 Agradecimientos a CONICYT Fondecyt Iniciacion No11130382, CONICYT Anillos SOC 1403, Centro CONICYT/FONDAP 15110020 (CEDEUS) y Grupo de Patrimonio GI 151701V/C UBB. Artículo recibido el 21 de abril de 2015, aceptado el 9 de julio de 2015 y corregido el 11 de septiembre de 2015.
2 Universidad del Bio Bio (Chile). E-mail:mlopez@ubiobio.cl

3 Universidad del Bio Bio (Chile). E-mail: ibisbal@ubiobio.cl

4 Investigador CEDEUS y Departamento de Urbanismo, Universidad de Concepción (Chile). E-mail: leperez@udec.cl 
Indudablemente el paisaje patrimonial minero $-y$ el caso de Lota es un ejemploestá íntimamente vinculado a los procesos de declive que se gatillan tras el cese de la actividad extractiva. Con el agravante de que, a diferencia de otros procesos de cambio productivo, el cierre minero se destaca por el volumen de trabajadores que cae en el desempleo, así como por la falta de opciones en zonas por lo general monoproductivas.

Por otra parte, se trata también de zonas en las cuales suele existir un fuerte sentido de pertenencia y cohesión social y una épica vinculada a la dureza del trabajo minero que junto con su legado tangible constituyen algunos de sus principales atributos.

Este trabajo se enmarca dentro de una línea de investigación desarrollada fundamentalmente desde fines de los años 90; la cual se enfoca a analizar el legado de la actividad minera histórica como un tipo particular de patrimonio industrial (Cole, 2004; AyalaCarcedo 2000; Carvajal y González, 2003; López y Vidal, 2012; López y Pérez, 2013; Orche, 2002a y 2002b; y Puche, 2003; Puche y Mazadiego, 2000 y 1997). Dentro de este ámbito la investigación se centró fundamentalmente en la dimensión paisajística de este patrimonio. El concepto de paisaje minero se utiliza oficialmente por primera vez en España el año 1993 con ocasión de la convención de Cultura de la Comunidad de Murcia ${ }^{5}$. Sin embargo, de acuerdo a Puche (2003), es a partir de la I Sesión Científica de la Sociedad Española de Patrimonio Geológico y Minero o SEDPGYM en $1996^{6}$, cuando se presentan diversas ponencias que destacan la profunda transformación del paisaje español a raíz de esta actividad; y este concepto empieza a estar más presente.

Si bien este tipo de paisajes comparte algunas de las características de otros sitios patrimoniales ${ }^{7}$, presenta singularidades particularmente desafiantes y complejas de abor-

\footnotetext{
5 Un año después de que la UNESCO acuñara el término "paisajes culturales con ocasión de la Convención de Patrimonio Mundial de ese mismo año.

6 Almadén, 21-22 de octubre de 1996.

7 Tales como su significancia para las comunidades locales, su importancia histórica, etc.
}

dar. Una de estas es la relación disonante que esta industria ha tenido históricamente con el medio ambiente; así como sus insostenibles relaciones con la fuerza de trabajo; particularmente durante el siglo XIX y hasta principios del siglo XX (Ortega, 1992: 137; Mazzei, 1997: 160 y 161).

Un tema adicional, ya señalado, son los procesos de declive que se desencadenan a partir del cierre de las actividades extractivas. Si bien algunos sitios sustentan importantes valores patrimoniales y paisajísticos, también muestran importantes grados de deterioro ambiental y socioeconómico. Es así como el desafío del marco regulatorio, más que referirse a cómo conservar paisajes culturales frente a los intereses especulativos (Zárate, 2011: 187), se enfrenta con la dificultad de impulsar procesos de reactivación que simultáneamente protejan los valores del paisaje cultural.

Ante este escenario, diversas administraciones locales han buscado la manera de impulsar procesos de recuperación ambiental y de regeneración urbana sobre la base del turismo patrimonial. Más allá de esta visión estratégica, la recuperación del legado cultural minero suele ser un anhelo compartido por muchas comunidades locales, que aprecian estos vestigios como evidencia tangible de su identidad local (López et al., 2010). Dentro de esta línea, un primer desafío es encontrar la forma de recuperar las cualidades del paisaje histórico, incorporando en este proceso las opiniones y apreciaciones de la comunidad local. Un concepto relevante al respecto es el de "biografía del paisaje" (Van der Valk, 2014: 159); el cual alude al objetivo de recoger narrativas del pasado que sean aún significativas en el paisaje actual (ya sea en términos escénicos, afectivos, etc.). La presunción implícita es que las narrativas pasadas pueden ser utilizadas como un instrumento de investigación a la vez que como una guía para futuros desarrollos, orientando de esta manera el planeamiento hacia un balance entre los objetivos de preservación y los de cambio. A partir de este enfoque el énfasis tradicional de la preservación del paisaje cultural como una manera de impedir el desarroIlo, se desplaza hacia una estrategia orientada más bien a encauzar y gestionar el cambio. 
Al respecto, se observa que los instrumentos usuales de planificación basados en el análisis cartográfico resultan extremadamente abstractos, dificultando la incorporación de aspectos cualitativos del paisaje así como la plena incorporación de la comunidad en el proceso de planificación. Por otra parte, las técnicas de análisis paisajístico basadas en la fotografía o el estudio en terreno han sido usualmente aplicadas para el análisis actual del territorio o su planificación futura sin desarrollar técnicas o metodologías específicas que vinculen el análisis del paisaje histórico a la planificación.

En este contexto, el presente artículo desarrolla una metodología que integra el análisis cartográfico con la repetición de fotografías como técnica de análisis comparativo del paisaje histórico y contemporáneo. El método permite desarrollar un trabajo arqueológico de redescubrimiento del paisaje cultural a partir de los vestigios que de este quedan en el paisaje actual a la vez que construye una interfaz cualitativa comprensible para las comunidades locales.

\section{La utilización y análisis de secuencias de fotografías de diferentes fechas}

\author{
Folch-Serra (2007:137) sostiene que:
}

"Puesto que lo ocular adquiere una centralidad sin precedentes en el mundo moderno, el impacto visual del paisaje se reviste de un nuevo significado", agregando que en la posmodernidad ocurre algo similar porque las interacciones "... dependen más y más de experiencias sociales construidas socialmente..."

La fotografía repetida de paisaje ${ }^{8}$ es una metodología que consiste en retratar repetida-

\footnotetext{
8 La juventud en el uso de esta técnica en español explica la confusión que existe actualmente para encontrar un término adecuado que la exprese. Se ha llegado a nombrar como refotografiado (o refotografiado), retrofotografiado o fotografía repetida. Concretamente, a 14 de julio de 2015 en el buscador Google Académico, aparece una referencia para "retrofotografiado", veinticinco para el término "refotografiado" y cuarenta para la expresión fotografía
}

mente un lugar reproduciendo las condiciones originales de toma fotográfica para poder observar los cambios y las dinámicas que se desarrollan en ese ámbito. Si bien esta técnica se ha empleado también con fotografía aérea, en el presente artículo nos referiremos exclusivamente a su uso en fotografías terrestres.

El origen del empleo de esta técnica de secuencia de fotografías en el tiempo hay que buscarlo en el campo de la geología, la biología, la ecología y las ciencias ambientales, utilizándose como herramienta que permite observar cambios producidos en el territorio. Si bien esta técnica es antigua, hasta la fecha no se ha sistematizado un método integrado que permita sacarle el mayor provecho a su potencial en el terreno del análisis paisajístico.

El uso de la fotografía repetida del paisaje se remonta a 1888 cuando Sebastian Finsterwalder comenzó a utilizarla en el estudio de glaciares mediante técnicas fotogramétricas. Posteriormente, estudios como los de Wooten (Wooten, 1916) y Shreve (Shreve, 1929; Shreve \& Hinckley, 1937) utilizaron la misma técnica a principios del siglo XX para el estudio de cambios en la vegetación. A partir de 1940 el uso de la fotografía repetida se volvió frecuente en el análisis de cambios en usos de suelo, cobertura vegetal y erosión. Es entonces cuando se comienza a utilizar la fotografía como elemento de comparación con crónicas de viaje (Lockett, 1939). En el campo de las ciencias ambientales y biológicas, el proyecto más antiguo a gran escala es el Desert Laboratory Repeat Photography Collection (Hastings \& Turner, 1965). Por otro lado, algunos estudios han utilizado esta técnica para observar cambios en el paisaje a partir de fotografías tomadas el siglo anterior, como ocurre en el caso de Johnson (Johnson, 1987), el cual fotografía de nuevo imágenes de William Henry Jackson para observar los cambios producidos en el paisaje de Wyoming, EE.UU. o Webb (Webb, 1996) con la

\footnotetext{
repetida, aquí utilizada. En inglés, el término más utilizado es repeat photography (2470 referencias) seguida de rephotography (1100 referencias). En francés se utiliza el término rephotographie (41 referencias, con su variante re-photographie), photographie diachronique (24 referencias) o photographie répétée (10 referencias).
} 
expedición de Stanton en el Gran Cañón del Colorado.

Prácticamente todos estos estudios se han centrado en paisajes naturales. En el caso de paisajes rurales o urbanos los trabajos son escasos y se han desarrollado con mayor profundidad en Europa ${ }^{9}$; si bien trabajos como el de Camilo José Vergara (Vergara, 1999) constituyen hitos tempranos en el ámbito americano. La referencia fundamental para este tipo de investigaciones es L'Observatoire Nationale du Paysage de France (OPP), creado en 1991 (Seguin y Soufflet-Leclerc, 2008). La metodología establecida por el OPP contempla la técnica de fotografía repetida, desde la definición de temas de estudio hasta el procedimiento técnico de la toma de la imagen. No sintetiza ninguna metodología de análisis posterior, confiando la labor de sintetizar las claves del paisaje a los documentos urbanísticos constituidos por los Atlas y las Cartas de Paisaje.

Desde el punto de vista del análisis de la imagen, las fotografías repetidas se han estudiado fundamentalmente mediante dos técnicas.

La primera, más antigua y más utilizada, consiste en redibujar sobre la imagen trazados que permiten analizar sus componentes principales. Esta técnica se ha utilizado frecuentemente en el campo de la geología para medir cambios dimensionales en glaciares o erosión en suelos, mientras que en biología se ha empleado para analizar asociaciones vegetales. En el campo de la geografía y el urbanismo su incidencia ha sido considerablemente menor y se ha vinculado más a cambios en la ocupación de suelo que a transformaciones de paisaje urbano.
La segunda técnica de análisis visual se ha introducido recientemente y consiste en contar puntos de distinto color en fotografía digital para hallar la proporción de superficie que ocupan los diferentes elementos de la imagen.

El presente estudio trata de construir una metodología sintética que reúne varias de estas técnicas de manera coordinada. Los principales antecedentes que se ha considerado en su desarrollo son el método del OPP junto con el estudio realizado en el valle de Vicdessos por Carré y Metailié (Carré y Metailié, 2008). En primer lugar, se han seleccionado imágenes de paisaje históricas representativas del período industrial minero de Lota. Posteriormente se han vuelto a fotografiar y se ha procedido a redibujar sobre la imagen los elementos que la componen. Finalmente, se han analizado las transformaciones producidas.

\section{Lota Alto como caso de estudio: el paisaje cultural y la importancia de la mirada}

La ciudad de Lota se ubica en la Región del Biobío, en la zona centro sur de Chile. Se encuentra en el extremo sur del Área Metropolitana de Concepción, y aproximadamente a 45 minutos en automóvil desde esta capital regional (Figura $\mathrm{N}^{0} 1$ ).

\footnotetext{
9 Véase los trabajos de Kull (2005) sobre fotografía repetida; de Bouisset et al. (2010) sobre el uso de las imágenes históricas para visualizar patrones de cambio del paisaje; o Lepart, Dervieux y Debussche (1996) sobre dinámicas de paisaje analizadas mediante fotografía.
} 
Figura $N^{\circ} 1$

Plano de Ubicación
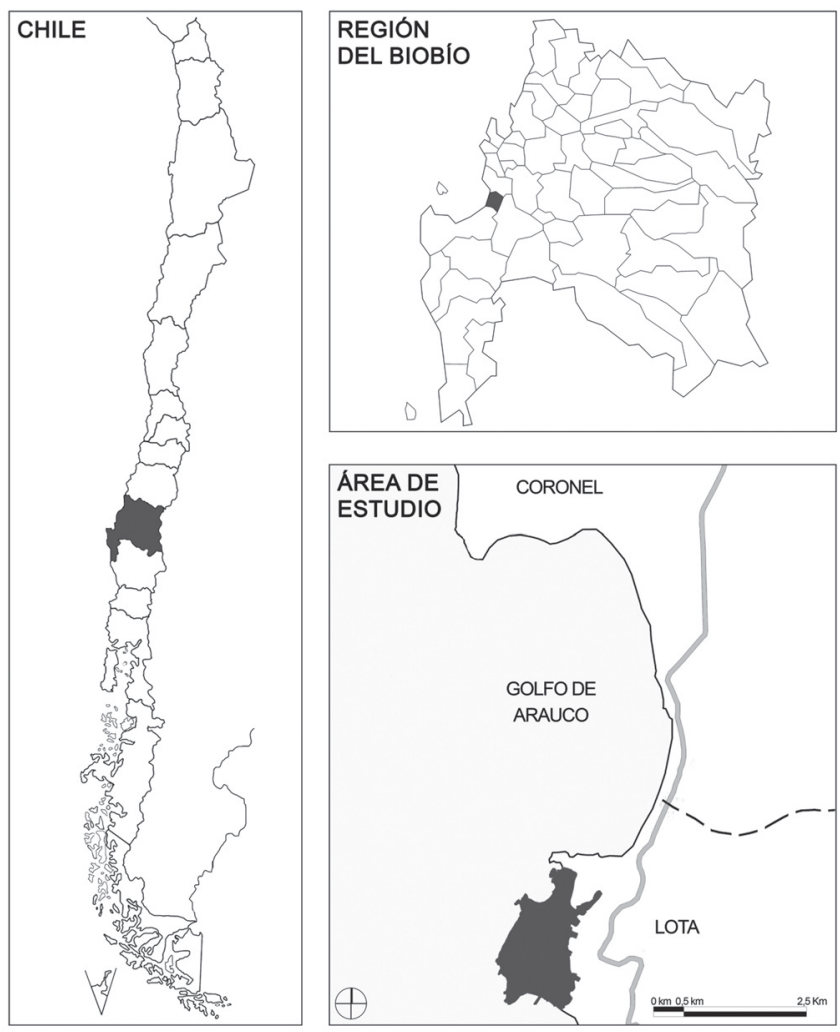

Fuente: Elaboración propia. Dibujo de N. Sandoval.

Esta ciudad podría sin lugar a dudas ser definida como el epicentro del desarrollo de la industria del carbón en Chile. Las primeras explotaciones datan de mediados del siglo XIX. Fueron impulsadas por la familia Cousiño, quienes fueran sus principales empresarios durante un siglo (Astorquiza y Galleguillos, 1952). En el año 1970 el Estado de Chile, a través de la Corporación de Fomento (CORFO), compra la mayoría de las acciones de la entonces Compañía Carbonífera Lota Schwager SA y en 1973 esta pasa enteramente a manos estatales como Empresa Nacional del Carbón (ENACAR). La crisis mundial de este mineral junto con los elevados costes de producción, entre otros factores, determinan que el año 1997 -tras una larga agonía- se cierren las minas.

La significancia de esta industria está dada tanto por lo temprano de su desarrollo -en los albores del despegue industrial en Chile- como por la importancia que alcanzara tanto en términos de los volúmenes de producción como del encadenamiento productivo aparejado. Fuera de las dimensiones estrictamente productivas, su importancia patrimonial radica también en los cambios económicos y sociales experimentados por un extenso territorio, en la introducción de nuevas tecnologías, la generación de nuevas formas de energía y el surgimiento de las ciudades del carbón como un nuevo tipo de paisaje patrimonial.

En términos urbanos la importancia de la ciudad de Lota radica en el grado de desarrollo alcanzado así como en las innovaciones implementadas a partir de tecnologías impulsadas con fines productivos tales como luz, agua, etc. Otro factor relevante fue la construcción -sobre todo a partir de principios del siglo XX-de importantes poblaciones obreras impulsadas por la propia compañía minera $y$, en menor medida, por el Estado. 
Los elementos construidos más significativos desde un punto de vista patrimonial se ubicaron en el sector de Lota Alto, donde se ubicó el histórico campamento minero (Fig. 1): los piques y chiflones para obtener el carbón, la fábrica de ladrillos refractarios (1854), la fundición de cobre (1857), el mueIle (1862), la maestranza y astillero de Chambeque (1870), la fábrica de vidrios (1881), la fábrica de gas (1882) y la central hidroeléctrica de Chivilingo (1897), la segunda en Sudamérica, que se mantuvo en funciones hasta 1975 (Muñoz et al., 2006: 33). A diferencia de la mayoría de las ciudades chilenas, estos elementos no se estructuraron en base a principios cartesianos de composición ni en unidades asimilables a manzanas, sino más bien en base al relieve (Figura $N^{\circ} 2$ ). De esta manera, los pabellones de viviendas se dispusieron sobre la meseta y las instalaciones industriales en los promontorios y en los fondos de las quebradas, a orilla del mar.

\section{Importancia de la mirada en Lota}

Si bien desde el ámbito científico algunos autores critican la hegemonía de la visión en la arquitectura, diversos autores reconocen su importancia. Es así como Pallasmaa la señala como "el más noble de los sentidos..."; destacando que "... el propio pensamiento se ha considerado en términos visuales" (2006: 15); similarmente, Zusman afirma que "la mirada media en la relación entre mundo y representación" (2004: 3); y Aliata y Silvestri destacan el paisaje como un último "momento" en el pensamiento occidental en el cual la visibilidad y el conocimiento del mundo aparecen unidos; reflexión que les lleva a sostener que la historia del paisaje sería de hecho la historia de las miradas (1994: 11).

En el caso del paisaje de Lota, la importancia de la mirada en su conformación constituye una de sus características distintivas. Es así como la estrecha relación que existe entre el tejido construido y el accidentado relieve queda expresada en una serie de vistas y secuencias visuales. Muñoz et al. (2006) ${ }^{10}$ constata la

\footnotetext{
10 A partir de la encuesta denominada "Percepción de los sectores y elementos Patrimoniales de Lota". Se trató de una muestra aleatoria realizada en la ciudad de Lota a 100 habitantes, de los cuales 39 eran
}

importancia del paisaje para los habitantes y cómo estos lo relacionan principalmente con su entorno natural y todo lo que conforma el paisaje construido (pabellones, edificios, plazas, parques, iglesia), etc. Se descubre que los espacios más importantes son para ellos: el Parque de Lota, los cerros, el mar, los miradores y Playa Blanca; y algunos de los elementos edificados más relevantes: los piques, la Plaza de Armas, la feria libre, el fuerte, el muelle antiguo y el cementerio. Los miradores de Lota han sido también destacados en el trabajo de Pérez (2009: 109) como elementos estructurantes de este paisaje cultural; en tanto constituyen espacios que, superando el mero hecho geográfico, conectan al habitante con su historia. La mirada, las vistas y los miradores son elementos clave de revalorización del paisaje cultural en tanto trascienden la dimensión tangible y reflejan la interacción entre las personas y su ambiente (Pérez, 2008).

En los últimos diecisiete años las acciones de las diferentes agencias y administraciones del Estado han incluido una serie de medidas, en su mayoría contradictorias. Si bien desde la Agencia Nacional de Protección del Patrimonio $^{11}$ se ha avanzado significativamente en la protección de diversos íconos, la falta de una normativa local que proteja las áreas históricas, entre otros factores, ha permitido que importantes vistas se hayan alterado. De ahí que el presente estudio intente medir la persistencia y pérdida de las vistas históricas en el paisaje contemporáneo de Lota Alto.

\section{Metodología}

El procedimiento aplicado ha sido desarrollado a partir de una investigación académica de dos años de duración (2014 a 2015). En síntesis, el método desarrollado consideró tres fases: a) recopilación y selección de fotos históricas. La fase de selección de las vistas

hombres y 61 mujeres. De las 37 preguntas de la encuesta 10 estaban relacionadas directamente con el paisaje urbano, qué elementos lo conformaban, la importancia que tenía, etc. Al preguntarle a habitantes qué era lo que más les gustaba de la ciudad, 73 personas señalaron que la belleza del paisaje y del entorno, lo que muestra cómo se identifican con su paisaje urbano y lo consideran un elemento atractivo y singular.

${ }^{11}$ Consejo Monumentos Nacionales (CMN). 
consideró también una parte de trabajos focales y entrevistas en profundidad con la comunidad con el fin de seleccionar aqueIlas que tenían una especial significancia; b) ubicación de los puntos de captura en cartografía SIG e identificación de las cuencas visuales o isovistas; c) repetición de fotografías históricas y procesamiento digital de las imágenes históricas y actuales; y por último d) identificación de los principales patrones de cambio a partir del análisis integrado de las vistas y la cartografía. En este artículo nos centraremos precisamente en el análisis de esta última fase.

Las fuentes consultadas en la fase de recopilación de imágenes históricas incluyeron el diario La Opinión de Lota ${ }^{12}$, archivos de la empresa minera ENACAR, fotografías de viajeros decimonónicos, archivos de residentes y agrupaciones de la comunidad y archivos nacionales. De esta manera se logró reunir un total de casi 400 imágenes históricas que reflejaban distintas vistas de la ciudad de Lota (Alto y Bajo) y alrededores de la primera mitad del siglo $\mathrm{XX}^{13}$.

A partir del análisis contrastado de vistas y cartografías históricas y actuales, se verificó la existencia de 4 sectores relativamente homogéneos, ya planteados por López y Vidal (2012): a) las áreas productivas; incluyendo tanto las áreas de piques como de instalaciones industriales y muelle de embarque; b) el campamento minero de Lota Alto; c) el Parque Isidora Cousiño, creado inicialmente como un espacio privado de los propietarios de la empresa minera; y d) Lota Bajo, donde se ubicó la ciudad pública.

A partir de esta sectorización, consulta a la comunidad local y revisión bibliográfica sobre la historia minera, se definieron itinerarios de repetición de fotografías que incorporaron vistas de las siguientes áreas ${ }^{14}$ :

\footnotetext{
12 Diario de la compañía minera.

13 Desde 1906 hasta 1959.

14 Un sector representativo que no se consideró fue el Parque Isidora Cousiño, dado que -en su condición de Monumento Histórico- los procesos de cambio son un factor menos relevante que en otros sectores más expuestos a dichas fuerzas.
}

- Áreas Productivas: chiflón, piques y muelle

- Ex campamento minero de Lota Alto

- Lota Bajo

La fase de consulta a la comunidad local incluyó la realización de dos grupos focales (uno con mujeres y otro con hombres); dos entrevistas en profundidad y un taller. El grupo de mujeres incluyó a 2 hijas y una nieta de ex minero. El de hombres incluyó a dos adultos mayores ex mineros y un hijo de minero. Uno de los ex mineros fue luego entrevistado en profundidad. La segunda entrevistada en profundidad fue una mujer, nieta, hija y esposa de minero. Tanto los grupos focales como las entrevistas se realizaron a modo de conversación y reconocimiento de recuerdos asociados a lugares a partir de la revisión de fotografías históricas. Dentro de este formato semiestructurado se abordaron de manera muy flexible cuatro temas: a) Lugares de la zona minera que más les gustaban; b) cambios que ha sufrido el lugar; c) aspectos que no les gustaban de la época minera; d) lugares que les disgustaban y e) expectativas de futuro y prioridades. Las consultas se realizaron en un centro cultural y una ONG, ambos en Lota Alto ${ }^{15}$. Adicionalmente, se realizó un taller con niños de $8^{\circ}$ básico de la Escuela Thompson de Lota, que involucró el reconocimiento y selección de imágenes históricas ${ }^{16}$. En los grupos focales y entrevistas participaron dos investigadores. Uno encargado de dirigir la conversación con los entrevistados y otro a cargo del registro por medio de vídeo y notas. En los talleres participaron dos investigadores y un asistente de investigación.

A partir de este proceso se seleccionó un total de 21 imágenes para repetición de fotografías. En terreno se debió descartar la realización de dos, dado que los cambios en el paisaje hacían imposible acceder a los sitios originales de captura ${ }^{17}$. Las fotografías fueron

\footnotetext{
${ }^{15}$ Centro Cultural Pabellón 83 y ONG la Casa de la Mujer.

${ }^{16}$ Corresponde en Chile a niños de aproximadamente 13 y 14 años. Taller realizado en la Escuela 18/6/2014 de 9:45 - 11:45 h.

17 Las dos imágenes descartadas corresponden a vistas del muelle de Lota, capturadas desde la falda suroriental del Parque de Lota.
} 
tomadas por estudiantes de arquitectura y arquitectos recién egresados, los cuales contaron con la colaboración de la comunidad para ubicar las vistas históricas menos reconocibles en el paisaje contemporáneo.

Paralelamente, se ejecutaron las cuencas visuales utilizando la herramienta cuenca visual del módulo 3D Analyst de ArcGis 10.2, y tomando como imagen raster de entrada un Modelo Digital de Terreno (MDT) de resolución $5 \times 5 \mathrm{~m}$. El MDT utilizado fue realizado en octubre de 2012 con las coordenadas UTM WGS 84 SIRGAS H18S18; y aplicando tecnología Light Detection and Ranging (LIDAR ${ }^{19}$ ) Trimble 68i que incorpora un sensor con cámara digital modelo ROLLEI, TAC AICpro P65+.

El trabajo de fotografiado buscó aproximarse a la composición histórica a partir de la localización de los puntos de captura originales y el ajuste de las longitudes focales de lente. Todas las fotografías fueron realizadas en modo manual, con trípode y en formato RAW para permitir su edición posterior sin pérdida significativa de calidad en la imagen. Se utilizó cámara profesional Nikon D-3000, con lentes de longitud focal variable de 18$55 \mathrm{~mm}$ y $35-70 \mathrm{~mm}$.

\section{Procesamiento digital y análisis del cambio}

La técnica aplicada consideró la superposición de las imágenes histórica y actual mediante programa de edición gráfica y el análisis del cambio para las categorías de elementos del paisaje antes señaladas. Para cada categoría se analiza el grado de "permanencia" y "alteración" de acuerdo a las variables que se indican en el Cuadro $N^{\circ} 1$.

El tratamiento de las imágenes básicamente incluyó las siguientes labores: a) mejora-

\footnotetext{
18 Las dos imágenes descartadas corresponden a vistas del muelle de Lota, capturadas desde la falda suroriental del Parque de Lota.

${ }^{19}$ Esta tecnología utiliza el mismo principio que el radar; se transmite un rayo de luz al suelo y se mide el tiempo que tarda en volver. Se diferencia del sistema radar en su habilidad para definir áreas pequeñas y para penetrar la vegetación http://www. lidarus.com/lidar/
}

miento de las fotografías históricas mediante edición con filtros, aumento de contraste y ajuste de histograma y curvas de canales RGB en el programa de edición de imágenes; b) recorte de encuadre y desaturación de las fotografías actuales; c) superposición de fotografías histórica y actual haciendo coincidir formas y encuadre, y variando la opacidad de las capas de cada una para verificación. También se usaron herramientas de selección para la separación de elementos comparados en cada imagen; y c) redibujo de áreas mediante trazado y aplicación de máscaras de color con diferentes grados de opacidad.

Es importante subrayar que el énfasis de la investigación es la escala urbana y territorial, razón por la cual los detalles que podrían apreciarse a escala arquitectónica o incluso constructiva no se consideraron; en tanto no resultaban relevantes o incluso perceptibles a esta escala ${ }^{20}$. Finalmente, dado el énfasis en la recuperación de vistas históricas, un objetivo importante de este proceso fue identificar -no solo la permanencia o el cambio de los elementos en sí (edificaciones, relieve, etc.)- sino también cambios en la visibilidad y el protagonismo que estos elementos tenían desde los antiguos miradores y puntos de captura.

Como se observa en el Cuadro $N^{\circ} 1$, las principales variables analizadas respecto de la categoría "suelo" fueron:

- Cambios en el área de suelo visible desde el punto de vista histórico

- Cambios relevantes (i.e. observables a simple vista ) en la pendiente

- En las vistas panorámicas, cambios en el tipo de ocupación del suelo; por ejemplo desde una situación "no urbanizada" a "urbanizada". Para los suelos "no urbanizados" que mantenían tal condición; también se consideró como alteración, los cambios relevantes en el tipo de cubierta vegetal (ej. desde una situación sin o con escasa vegetación, a suelo vegetado).

\footnotetext{
20 El componente del color -que sí es usualmente considerado en los análisis del paisaje- tampoco se consideró dado que las fotos históricas carecían de dicha información.
} 
Cuadro $\mathrm{N}^{\circ} 1$

Categorías de análisis del cambio del paisaje

\begin{tabular}{|c|c|c|c|c|}
\hline \multirow{2}{*}{ Categorías } & \multicolumn{2}{|c|}{ Permanencias } & \multicolumn{2}{|c|}{ Alteraciones } \\
\hline & Total & Parcial & Elimina & Agrega \\
\hline Edificación & $\begin{array}{l}\text { Se mantiene la edificación } \\
\text { histórica con todas sus } \\
\text { características }\end{array}$ & $\begin{array}{l}\text { Se mantiene la edificación pero } \\
\text { algunas de sus características } \\
\frac{\text { se han modificado (ej.: parte }}{\text { de la materialidad, algunos }} \\
\text { elementos de fachada, etc.). }\end{array}$ & $\begin{array}{l}\text { La edificación pre- } \\
\text { existente ha desapa- } \\
\text { recido. }\end{array}$ & $\begin{array}{l}\text { Se ha agregado } \\
\text { una nueva } \\
\text { edificación. }\end{array}$ \\
\hline Infraestructura & $\begin{array}{l}\text { Se mantiene la infraes- } \\
\text { tructura histórica (vías, } \\
\text { puentes, túneles, muelles, } \\
\text { y mobiliario urbano) con } \\
\text { todas sus características }\end{array}$ & $\begin{array}{l}\text { Se mantiene la infraestructura } \\
\text { histórica pero algunas de sus } \\
\text { características se han modi- } \\
\text { ficado (ej.. Para vías: trazado } \\
\text { y pavimento; para mobiliario } \\
\text { urbano: tipo y estilo) }\end{array}$ & $\begin{array}{l}\text { La infraestructura } \\
\text { preexistente ha desa- } \\
\text { parecido. }\end{array}$ & $\begin{array}{l}\text { Se ha agregado } \\
\text { una nueva in- } \\
\text { fraestructura. }\end{array}$ \\
\hline Vegetación & $\begin{array}{l}\text { Se mantiene el mismo tipo } \\
\text { y densidad de vegetacion } \\
\text { presente en la imagen } \\
\text { histórica (tipo arbustivo, } \\
\text { arbóreo o pradera) }\end{array}$ & $\begin{array}{l}\text { Se mantienen algunas de las } \\
\text { características de la vegetación } \\
\text { pero algunas de sus caracterís- } \\
\text { ticas se han modificado (tipos, } \\
\text { altura o densidad) }\end{array}$ & $\begin{array}{l}\text { La vegetación pre- } \\
\text { existente ha desapa- } \\
\text { recido. }\end{array}$ & $\begin{array}{l}\text { Se ha agregado } \\
\text { vegetacion. }\end{array}$ \\
\hline \multirow[t]{2}{*}{$\begin{array}{l}\text { Cuerpos de } \\
\text { agua }\end{array}$} & $\begin{array}{l}\text { Se mantienen los mismos } \\
\text { cuerpos de agua presentes } \\
\text { en la imagen histórica } \\
\text { (forma y extensión) }\end{array}$ & $\begin{array}{l}\text { Se mantienen algunas de las } \\
\text { características del cuerpo de } \\
\text { agua pero algunas de sus ca- } \\
\text { racterísticas se han modificado } \\
\text { (forma o extensión) }\end{array}$ & $\begin{array}{l}\text { El cuerpo de agua } \\
\text { preexistente ha desa- } \\
\text { parecido. }\end{array}$ & $\begin{array}{l}\text { Se ha agregado } \\
\text { un cuerpo de } \\
\text { agua donde } \\
\text { previamente no } \\
\text { existía. }\end{array}$ \\
\hline & Mantiene & & Modifica & \\
\hline Relieve & $\begin{array}{l}\text { Se mantiene el relieve } \\
\text { histórico (pendientes, de- } \\
\text { presiones, taludes, etc.) }\end{array}$ & $\mathrm{N} / \mathrm{A}$ & $\begin{array}{l}\text { El relieve preexistente } \\
\text { o histórico ha sido } \\
\text { modificado (pendien- } \\
\text { tes aplanadas, taldes } \\
\text { modificados, etc.) }\end{array}$ & $\mathrm{N} / \mathrm{A}$ \\
\hline
\end{tabular}

Fuente: Elaboración propia.

Con respecto a los cambios en la pendiente, y dado que se trataba de identificar cambios observables a simple vista, básicamente se consideraron cuatro categorías: suelos perceptualmente planos, suelos con pendiente leve, suelos con pendiente pronunciada y desfases verticales de dos áreas de suelo (o 100\% de pendiente). En concreto, se buscó identificar aportes o sustracciones de suelo tales como desmontes, terraplenes, apisonados, construcción o eliminación de plataformas, entre otras alteraciones significativas del relieve.

Para medir y visualizar la permanencia de las características del suelo se realizó en cada vista el siguiente procedimiento:

a) Se identificaron los tipos de suelo observables en las fotografías históricas; entendiendo por ello aquellas superficies de pavimento que mantenían una continuidad y homogeneidad en términos de pendiente y tipo de ocupación/cubierta vegetal.

b) En la misma imagen histórica se trazó el contorno de cada tipo de suelo; identificando de esta manera uno o varios polígonos; de manera que cada polígono representara un tipo de suelo (S1, S2, etc.).

c) Se superpuso la imagen histórica con los polígonos sobre la vista actual. Luego -a partir de sucesivas modificaciones en la opacidad/ transparencia de ambas imágenes- se identificaron las áreas que habían sufrido alteraciones ya sea en cuanto a la geometría del área de suelo observable o en cuanto a las variables de pendiente, tipo de ocupación o cubierta vegetal.

d) Finalmente, se trazó el contorno de estas áreas de alteración (A1, A2, etc.)

\section{Vistas analizadas}

El total de imágenes procesadas se muestra en el resumen de vistas analizadas, ordenadas por sector (Cuadro $\mathrm{N}^{\circ} 2$ ). Corresponden a diecinueve vistas de las primeras décadas a mediados del siglo XX, comparadas con las vistas al año 2014. 


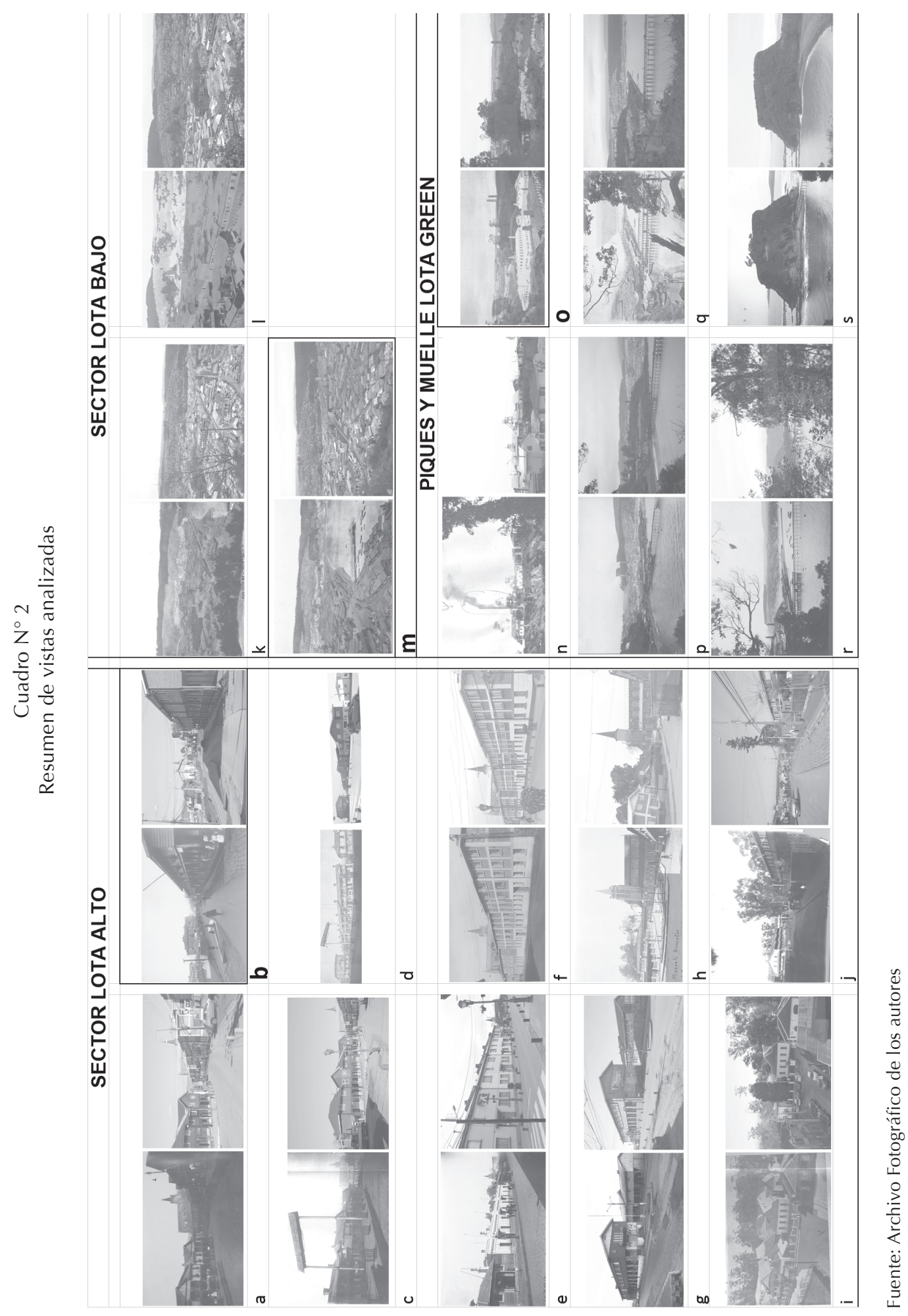


A continuación se describe la aplicación de este trabajo en tres vistas representativas de cada uno de los tres sectores señalados. La primera corresponde a una vista de la Avda. Cousiño en el Sector de Lota Alto: vista ' $b$ '. La segunda corresponde a una imagen panorámica de Lota Bajo, capturada desde uno de los antiguos miradores de Lota Alto: vista ' $\mathrm{m}^{\prime 21}$. Finalmente, la última vista abarca la fábrica de Cerámicas de Lota Green capturada desde un antiguo mirador del Parque de Lota: vista 'o' (Figura $\mathrm{N}^{\circ}$ 2). Tanto el parque como la fábrica han sido declarados Monumentos Históricos. El primero constituye una de las obras paisajísticas más destacadas de la época en Chile, impulsada por los propietarios de la Compañía Minera y la segunda corresponde a una de las industrias más relevantes derivadas de la actividad minera, cual fue la producción de cerámicas, ladrillos refractarios y posteriormente objetos de porcelana (Astorquiza, 1952).

Figura $\mathrm{N}^{\circ} 2$

Ubicación de puntos de captura de vistas históricas

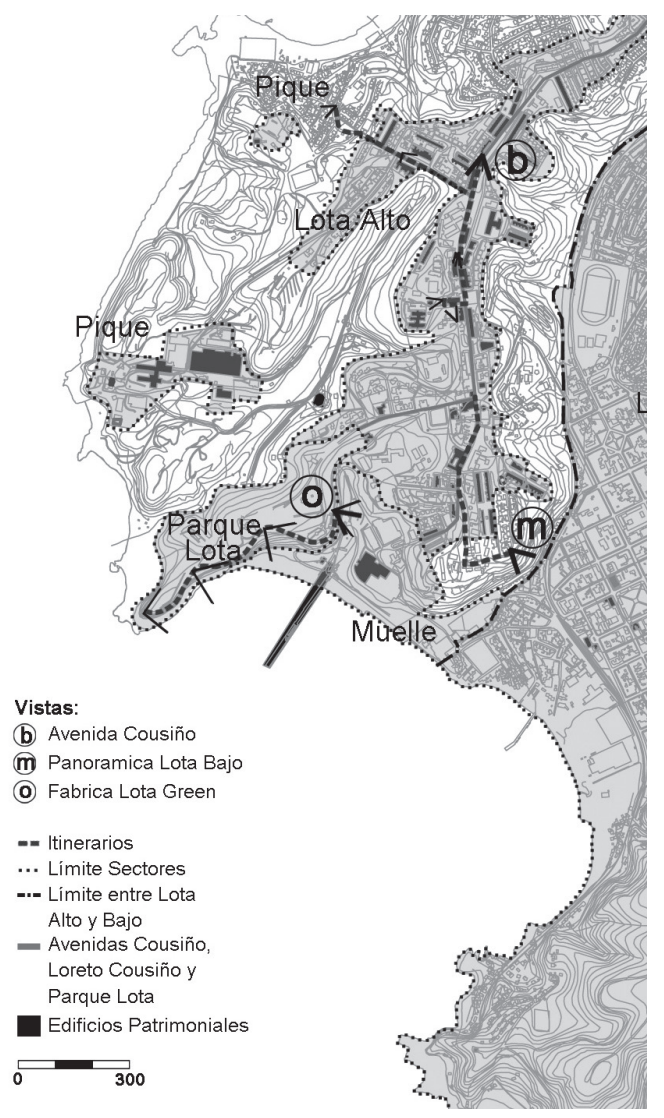

Fuente: Elaborado propio a partir de proyecto de plan regulados comunal de lota. dinujo de J. Garrido y N. Sandoval ley 17.288 , corresponde a una de las herramientas de protección del patrimonio en Chile, que se considera significativo a nivel nacional. 
Vista 'b' - Avda. Cousiño

En la foto histórica se captura una vista de la Avda. Cousiño, en dirección sur; capturada en las primeras décadas del siglo XX.

Figura $N^{\circ} 3$

Analisis categoria suelo Av. Cousiño

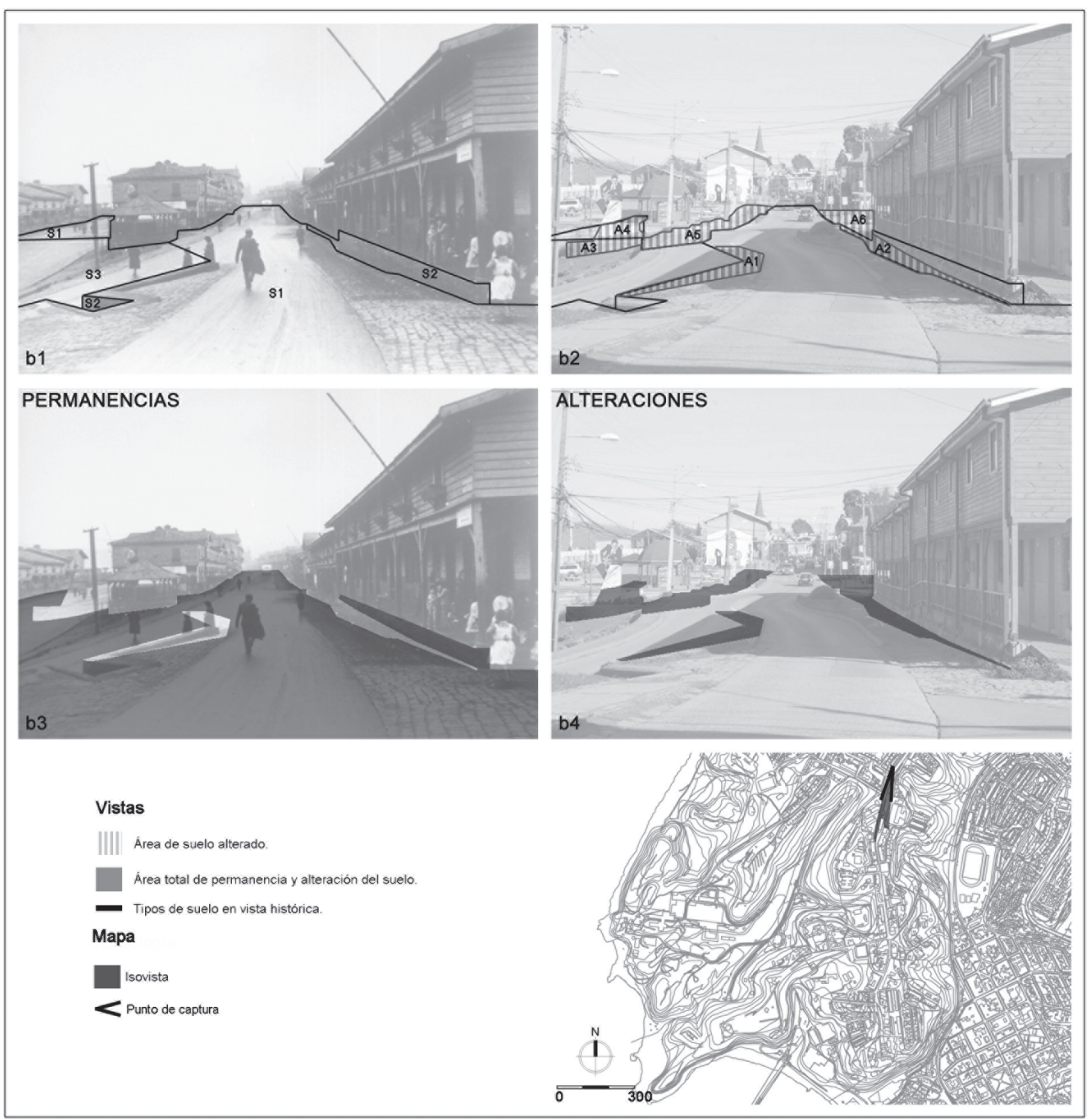

Se identifican los tipos de suelo, las alteraciones y las áreas totales de permanencia y de alteración del relieve en la Vista b (b1, b2, b3 y b4 respectivamente). En la planta se indica el área visible.

Fuente: Elaboración propia. Dibujo de J. Garrido en base a fuente vista histórica archivos Centro Cultural Pabellón 83. Vista actual, archivo fotográfico de los autores. 
Se identifican en esta vista tres tipos de suelo: S1 perceptualmente plano; S2 que corresponde a los muros de contención de los corredores ( $100 \%$ de pendiente); y S3 con pendiente leve (Figura $N^{\circ} 3$ ). Para cuantificar las áreas de 'permanencia' del suelo se sustraen de cada polígono aquellas áreas en las cuales las características del suelo se han visto alteradas (A1, A2, A3 y A4) ya sea por cambios en la pendiente, observables a simple vista a escala urbana, o cambios en el área de suelo visible (Figura $N^{\circ} 3$ ). De esta manera se obtiene que el área total de suelo que preserva las características de la vista histórica es igual a:

$$
\mathrm{S} 1-(\mathrm{A} 1+\mathrm{A} 4)+(\mathrm{S} 2-\mathrm{A} 2)+(\mathrm{S} 3-\mathrm{A} 3)
$$

Adicionalmente, vemos que se agrega un retazo de suelo plano en la zona intermedia de la vista (A5 y A6) debido a la eliminación de pabellones mineros y otras construcciones, ahora sustituidos por espacios abiertos. De esta manera se obtiene que el área total de Alteración del relieve es:

$$
\mathrm{A} 1+\mathrm{A} 2+\mathrm{A} 3+\mathrm{A} 4+\mathrm{A} 5+\mathrm{A} 76
$$

Como resultado de este análisis se observa un claro predominio de las áreas de permanencia sobre las áreas de alteración. En términos generales la vista actual de la Avda. Cousiño preserva la morfología de la avenida (Vistas b3 y b4 en Figura $N^{\circ} 3$ ); así como la diversidad de pendientes y niveles que caracterizaban al relieve de la vista histórica. Por otra parte, de acuerdo al tipo de alteraciones registradas, se observa que estas tienden a reducir el grado de configuración de la calle histórica, a partir de la incorporación de espacios abiertos, donde antes sendos pabe-
Ilones flanqueaban la avenida (Vista b4 en Figura $\mathrm{N}^{\circ} 3$ ).

\section{Vista 'm' - Panorámica de Lota Bajo}

En el ejemplo de la vista panorámica de Lota Bajo se identificaron dos tipos de suelo: S1 como suelo Ilano y S2 como cerro no urbanizado $^{23}$ (Figura $N^{\circ} 4$ ). Luego se superpusieron ambos polígonos en la foto actual, identificando para S1 y S2 aquellas áreas que habían sufrido alteraciones (A1, A2 y A3, en Figura $\mathrm{N}^{\circ} 4$ ).

Se observa que el área antiguamente ocupada por el mar y prácticamente la mitad de los cerros han sido ocupados por la expansión urbana. De esta manera el área de suelo que 'Permanece' se obtiene de: $\mathrm{S} 1+$ $\mathrm{S} 2-(\mathrm{A} 2+\mathrm{A} 3)$ (Figura $\mathrm{N}^{\circ}$ 6). $\mathrm{Y}$ el área de suelo "Alterada" se obtiene de: A1+A2 + A3.

A diferencia del caso anterior se observa una distribución más o menos equitativa entre las áreas alteradas y las áreas de permanencia (m3 y m4), siendo la expansión de las áreas urbanizadas el principal factor de cambio en una tendencia clara de alteración de los elementos naturales del paisaje.

\footnotetext{
${ }^{23}$ Cabe señalar que a diferencia del criterio aplicado en las fotografías de áreas urbanas, en las vistas panorámicas se incluyó dentro de los polígonos S1 y S2 la edificación y vegetación, que a esta distancia de visión se perciben como parte del relieve.
} 
Figura $N^{\circ} 4$

Análisis categoria suelo Lota Bajo

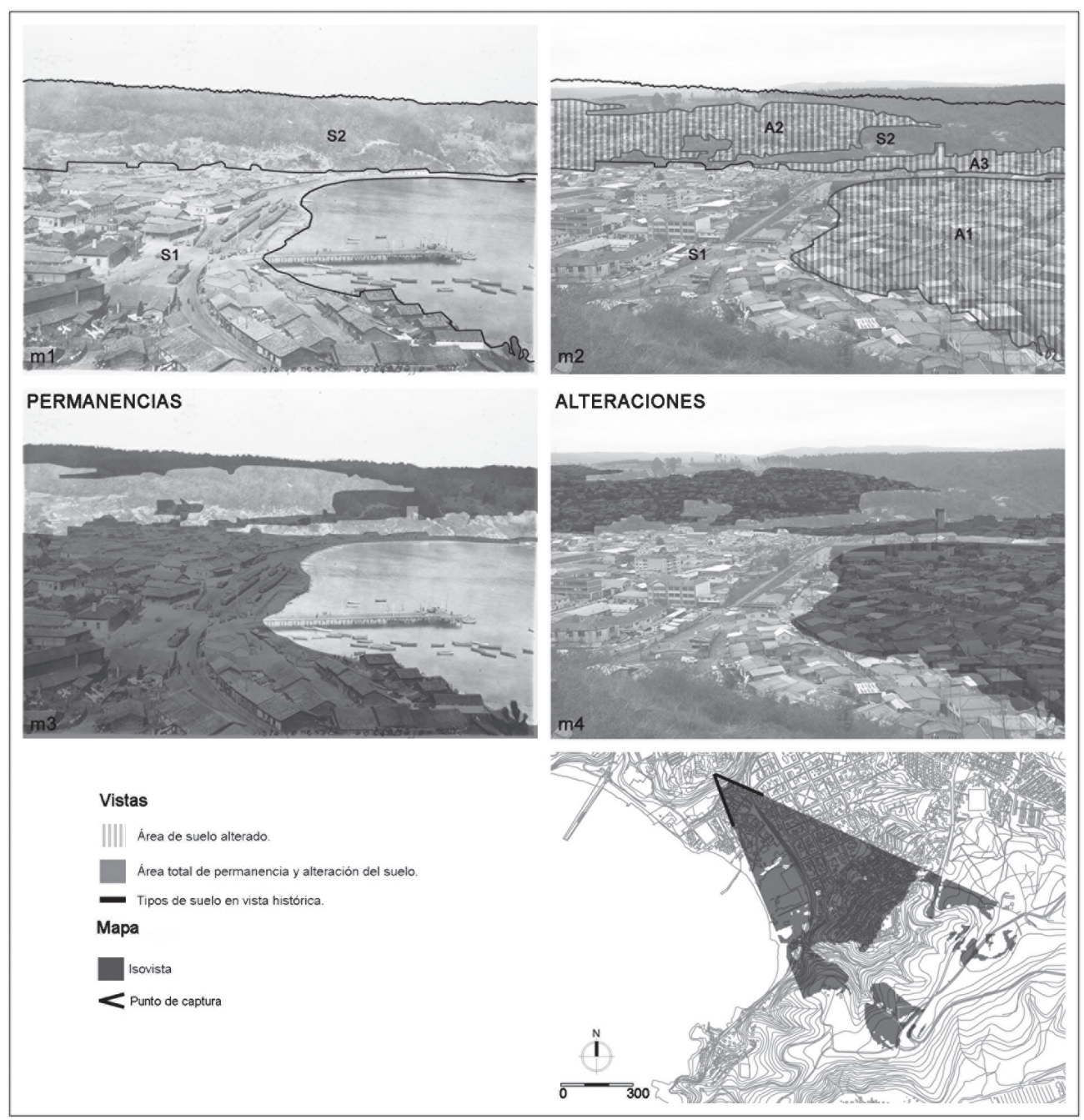

En la imagen $\mathrm{m} 1$ se observan los contornos de los suelos: Ilano (S1) y ladera no urbanizada (S2). En m2 se identifican las zonas de suelo alteradas por la ocupación urbana. En m3 y m4 se representan las superficies totales del relieve histórico que se preserva y que han sufrido alteraciones respectivamente. Fuente: Elaboración propia. Dibujo de J. Garrido en base a fuente vista histórica archivos UBB. Vista actual archivo fotográfico de los autores.

\section{Vista 'o' - Fábrica de Cerâmicas Lota Green}

En la antigua fábrica de cerámicas de Lota Green se identifican los siguientes tipos de suelo: suelo plano (S1), laderas no urbanizadas (S2); y ladera urbanizada (S3) (Figura № 5) ${ }^{24}$.

\footnotetext{
${ }^{24}$ Nótese que, a diferencia de la vista panorámica de Lota Bajo, a esta distancia más cercana de visión -al igual como ocurría en la vista de Avda. Cousiño- se dejan fuera de los polígonos los objetos ubicados en primer plano (edificaciones y arborización).
} 

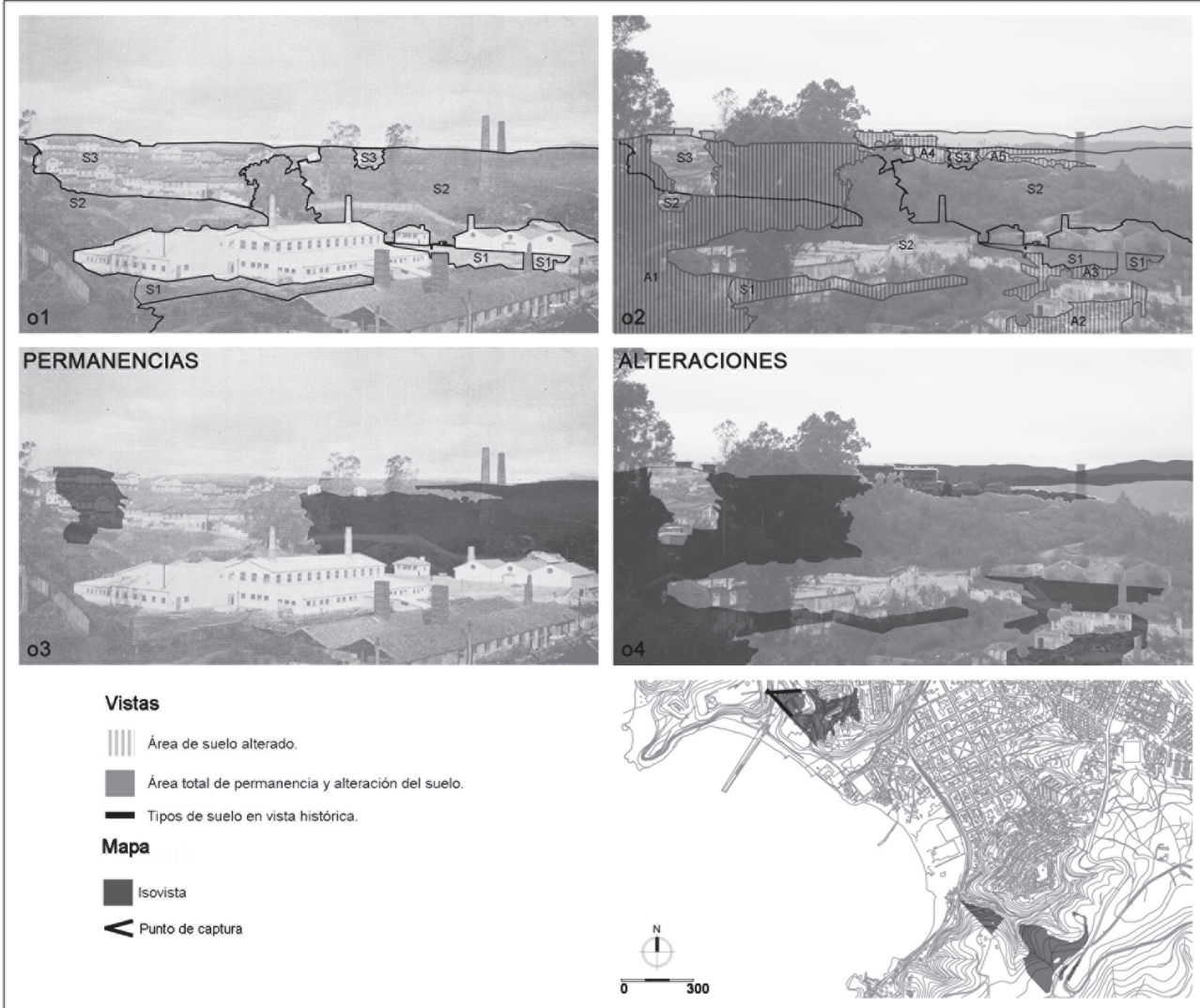

En Vista o1 se identifican tres Tipos de Suelo: plano (S1), cerro no urbanizado (S2) y cerro urbanizado (S3). En o2 se identifican las alteraciones producto de la ocupación urbana del cerro y la vegetación del primer plano. En o3 y o4 se representan las superficies del relieve en las cuales se preservan y se modifican las características del relieve histórico respectivamente. Fuente: Elaboración por C. Guzmán; fuente vista histórica Astorquiza (1952). Vista actual, archivo fotográfico de los autores.

Al superponer estos polígonos sobre la imagen actual se verifican las siguientes áreas alteradas:

- A1 corresponde al área de árboles y arbustos ubicados en primer plano que oculta parcialmente las áreas de suelo que eran visibles en la fotografía histórica.

- A2 y A3 corresponden a retazos de suelo visibles en la imagen actual producto del derrumbe parcial de antiguas instalaciones fabriles y hoy colonizadas espontáneamente por vegetación silvestre.

- A4 corresponde a áreas urbanizadas en lo que eran antiguamente cerros con cubierta vegetal.
De esta manera vemos que la mayor parte del relieve observable en la fotografía histórica se ha visto alterado; siendo los principales factores de esta alteración los siguientes:

- Sucesivos procesos de reedificación, abandono, ruina y 'renaturalización' del suelo en las antiguas áreas industriales.

- Arborización espontánea de antiguos puntos de vista panorámicos.

- Procesos de expansión urbana en los antiguos cordones de cerros que limitaban el asentamiento urbano. 


\section{Patrones de cambio del paisaje cultural minero}

A partir del análisis es posible identificar dos patrones de cambio en dos sectores claramente diferenciables. Por una parte, el tipo de transformaciones que ha afectado al ex campamento minero $y$, por otra, las transformaciones que han afectado a los sectores que en la época minera eran industriales o periurbanos (adyacentes a Lota Bajo).

Como se observa en la Figura $\mathrm{N}^{\circ} 6-\mathrm{Co}-$ rrespondiente Sector de Lota Alto- las áreas que preservan las características del suelo 'histórico' predominan claramente sobre los retazos alterados. Esto contrasta notablemente con la situación en las ex zonas mineroindustriales y periurbanas, donde los cambios son notablemente más relevantes.

En Lota Alto se procesaron un total de diez vistas históricas. Las fotografías retratan vistas cercanas (hasta los $300 \mathrm{~m}$ de longitud aproximadamente) y $30^{\circ}$ de apertura. En este rango el suelo visible corresponde básicamente a espacios exteriores ubicados entre los edificios, es decir: vías y plazas. El análisis demuestra en un efecto que resulta consistente con otros estudios sobre evolución de la forma urbana (ejemplo, Hall, 2015)- que uno de los elementos más persistentes ha sido la traza viaria; es así como, si bien los edificios han cambiado en algunos casos notablemente, la forma de las vías se mantiene. De esta manera, fue posible encontrar fácilmente los puntos de vista 'históricos' en el paisaje actual. Las alteraciones del relieve -cuando las hay- son de escasa cuantía en la mayoría de los casos. Por otra parte, resulta interesante notar que, en las alteraciones producidas, el sentido del cambio es hacia una homogeneización de las irregularidades del relieve a partir de los sucesivos procesos de reedificación (Vistas a y b, en Figura $\mathrm{N}^{\circ}$ 6). Adicionalmente, se observa un caso puntual de desaparición de un espacio público para ser ocupado por nuevas edificaciones habitacionales (Vista h en Figura $\left.N^{\circ} 6\right)^{25}$.

25 Este es el caso de la antigua Plaza de Bienestar.
En Lota Bajo, si bien se procesaron y analizaron solo tres imágenes (Cuadro $N^{\circ} 2$ ), se trata de vistas panorámicas que logran captar la manera en que se articulaba el poblado con el sitio de emplazamiento. Las fotografías retratan vistas lejanas capturadas desde un antiguo mirador de Lota Alto. Abarcan cuencas visuales que Ilegan hasta los $1.200 \mathrm{~m}$ de distancia aproximadamente y $180^{\circ}$ de apertura panorámica. Dentro de este ángulo, unos $60^{\circ}$ son los que alcanzan a ser registrados en la fotografía. Los cambios en la categoría suelo se deben fundamentalmente a la expansión urbana sobre los sistemas naturales. Es así como observamos el relleno y ocupación de la antigua zona de bahía; y la ocupación de amplios sectores de cerros (Figura $N^{\circ} 7$ ). El poblado en la vista histórica estaba 'confinado' por el mar y el relieve. En el paisaje actual en cambio, este equilibrio se ha roto a partir del 'desborde' del área urbana por sobre los sistemas naturales.

En las zonas industriales (piques y muelle en Lota Green) se procesaron un total de seis imágenes (Cuadro $\mathrm{N}^{\circ} 2$ ). Una vista retrata un sector de piques (Pique Grande). Las cinco restantes capturan, desde distintos miradores, la articulación entre las zonas industriales y el borde costero: una imagen retrata al sector de El Morro capturado desde el Chiflón del Diablo (Vista s en Figura $N^{\circ} 7$ ); y las otras cuatro al sector del muelle y Lota Green, desde el Parque de Lota. La mayoría de las imágenes retratan vistas lejanas en cuencas visuales que llegan hasta los $1.200 \mathrm{~m}$ de distancia aproximadamente, incluyendo la bahía de Lota Bajo.

Las transformaciones del suelo observadas en estos sectores se relacionan con los siguientes procesos. En primer lugar, el abandono o subutilización de las áreas mineroindustriales históricas, el cual ha resultado en dos tipos de transformaciones: en algunos casos la ocupación de estas áreas para uso habitacional, y en otros casos la colonización espontánea de antiguas ruinas industriales con vegetación silvestre (ver Pique Grande -vista n y Lota Green- vista o, en Figura No 7). Un segundo tipo de dinámica es la alteración del borde costero, producto de la acumulación de escorias derivadas de la actividad minera. Esto se aprecia en la imagen de El Morro, formación que históricamente se entendía como un islote, y que en la fotogra- 
fía actual aparece conectada al borde continental mediante una zona de relleno (Vista s en Figura $\mathrm{N}^{\circ} 7$ ). Finalmente, otro fenómeno es la pérdida de la condición panorámica de algunos miradores tales como el antiguo mirador desde el Parque de Lota hacia el muelle (Vista o en Figura $N^{\circ} 7$ ).

Figura $\mathrm{N}^{\circ} 6$

Dinámicas de cambio del suelo en Lota Alto

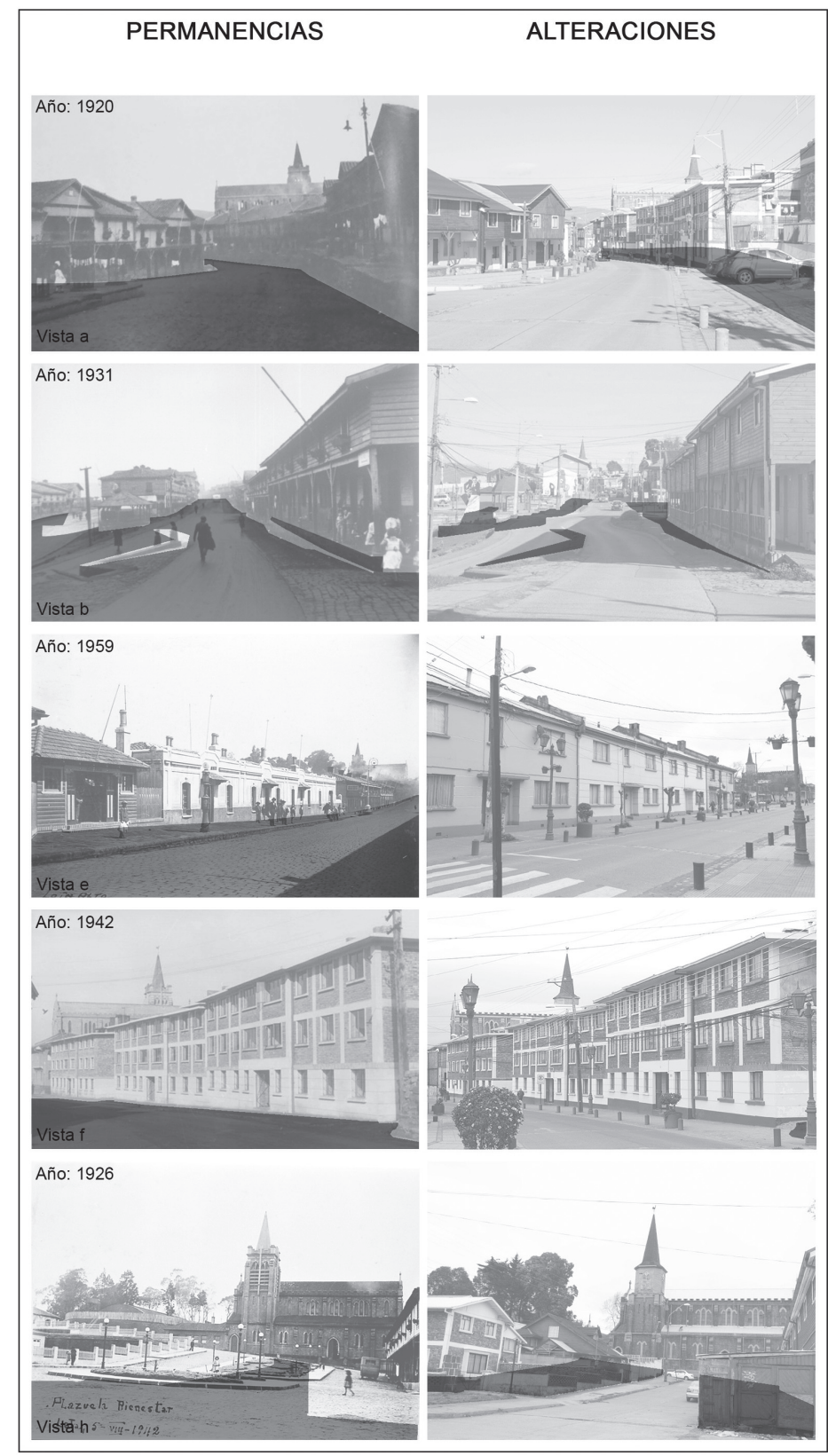

Fuente: Archivo fotográfico de los autores. Elaborado por C. Guzmán, J. Garrido y B. Sáez, en base a fuentes vistas históricas: Astorquiza (1952), Archivo UBB y Diario La Opinión de Lota. 
Figura $\mathrm{N}^{\circ} 7$

Dinámicas de cambio del suelo en Lota Bajo y áreas industriales

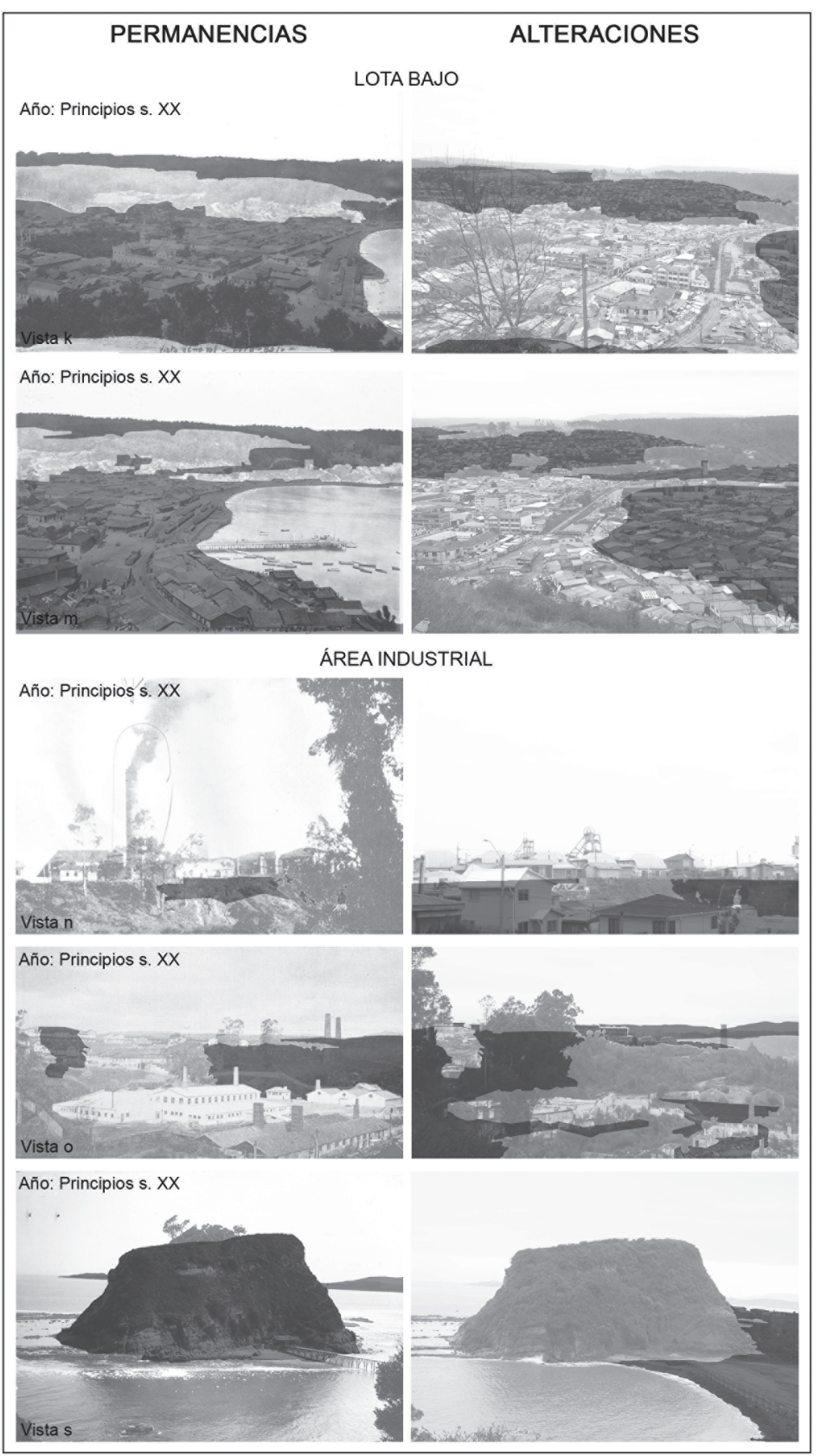

Fuente: Elaboración propia. Dibujo C. Guzmán, J. Garrido y B. Sáez; fuentes vistas históricas: Astorquiza (1952), Archivo UBB y Biblioteca Nacional. Vistas actuales, archivo fotográfico de los autores. 


\section{Conclusiones}

Las técnicas de fotografía repetida y análisis fotográfico han estado predominantemente orientadas hacia estudios de evolución geológica y de vegetación. De ahí que la experiencia desarrollada en el caso de Lota resulte novedosa en tanto que propone una manera de integrar estas herramientas en una metodología de análisis de ambientes urbanos de interés patrimonial.

Como fortalezas de la metodología, se comprueba que la fotografía repetida e interpretación del cambio a través de vistas puede ser un potente complemento a otras técnicas de análisis del paisaje, tales como el análisis a partir de cartografía en SIG y registro de las percepciones de los habitantes. En este sentido, el método logra interrelacionar y complementar estas distintas aproximaciones para analizar y apreciar las dinámicas de cambio desde un enfoque cualitativo. En segundo lugar, la fotografía repetida permite una aproximación mucho menos abstracta que facilita la incorporación de la comunidad -u otros actores interesados- en el proceso de planificación y gestión del paisaje patrimonial. En tercer lugar, se demuestra que integrar las perspectivas arqueológica y paisajística resulta especialmente apropiado para el caso específico de los paisajes culturales en declive, tal y como ocurre en el caso de los territorios postmineros. Esto se manifiesta en la medida en que la investigación arqueológica se utiliza para revelar los vínculos entre el paisaje contemporáneo y el paisaje histórico.

Por otra parte, una debilidad del método propuesto consiste en la dificultad de encontrar los puntos exactos de captura de las fotografías históricas, especialmente en zonas que han sufrido transformaciones muy drásticas. Sin embargo, este problema puede ser subsanado a partir de la información que puede aportar la propia comunidad, especialmente las personas mayores. En este sentido, esta dificultad puede verse también como una oportunidad en tanto que asigna un rol relevante a la colaboración entre los habitantes y el equipo técnico encargado del registro fotográfico. Una segunda dificultad es que el método requiere de un trabajo delicado de procesamiento gráfico, lo que implica una capacitación inicial y un tiempo considerable de procesado en gabinete. Por otra parte, este mismo trabajo tiene como contrapartida favorable que el proceso de análisis construye un material visual atractivo que puede ser usado con fines de difusión del patrimonio, así como para ser empleado en campañas de educación ambiental a la comunidad al reflejar de manera fácilmente aprehensible la fragilidad del paisaje y la potencia de las dinámicas de cambio.

Finalmente, en cuanto a las dinámicas de cambio detectadas, se concluye que, en el caso de Lota, las áreas de asentamiento que alcanzaron a consolidarse durante la época minera han sido las más resilientes frente al cambio. En contraste, las transformaciones del paisaje han sido mucho más significativas tanto en las zonas minero-industriales como en las zonas que en esa época tenían una condición periurbana. La alteración del suelo en estas últimas replica una dinámica frecuente en ciudades chilenas ${ }^{26}$ consistente en la ocupación urbana de los sistemas naturales del emplazamiento. Por otra parte, la transformación del suelo en las áreas mineroindustriales abandonadas puede entenderse como un fenómeno particular de este tipo de enclaves que se caracteriza por la convergencia de dos fuerzas opuestas: Por una parte, la tendencia desarrollista de ocupar las antiguas áreas abandonadas $y$, por otra, la resistencia de estas áreas frente a la ocupación (producto del riesgo ambiental o del régimen de propiedad del suelo entre otros). Esto último explica la presencia de grandes paños eriazos adyacentes a zonas centrales; situación que determina la fragmentación característica del tejido urbano de estos poblados.

Para finalizar, consideramos que este fenómeno puede leerse como un problema (de accesibilidad, de conectividad, imagen unitaria, presencia de áreas inseguras, subutilización económica del suelo, etc.), pero también como una oportunidad en tanto la resistencia al cambio ha preservado vestigios de la historia minera que de otra manera podrían haber desaparecido completamente. En este escena-

\footnotetext{
26 Como ejemplo véase el caso de Concepción en López y Vidal, (2014).
} 
rio, el redescubrimiento y puesta en valor de la mirada abre una puerta a la reconstitución de la historia de vida del paisaje.

\section{Referencias bibliográficas}

ALIATA, F. y SILVESTRI, G. El paisaje en el arte y en las ciencias humanas. Buenos Aires: Centro Editor de América Latina, 1994.

ASTORQUIZA, O. Lota: antecedentes históricos, con una monografía de la Compañía Minera e Industrial de Chile. Concepción: Sociedad, Imprenta y Litografía Concepción, 1929.

ASTORQUIZA, O. y GALLEGUILLOS, V. Cien años del carbón de Lota. Santiago de Chile: Editorial Zig-Zag, 1952.

AYALA-CARCEDO, F.J. Patrimonio Natural y Cultural y Desarrollo Sostenible: El patrimonio Geológico y Minero. En: RÁBADO, I. (editora). Patrimonio geológico y minero en el marco del desarrollo sostenible. Madrid: IGME. Serv. Publ. Min. Cienc. Tecnol. Madrid, España: 8. Actas del Congreso Internacional sobre Patrimonio Geológico y Minero en el Marco del Desarrollo Sostenible y V Sesión Científica de la SEDPGYM, Esc. Univ. Politécnica. Linares (Jaén) 20 al 22 de octubre, 2000.

BASAURE, C. Estudio de la relación paisaje-ciudad en el asentamiento minero de Lota Alto. Concepción: Seminario de Título, Facultad de Arquitectura, Construcción y Diseño, Universidad del Biobío, 2005.

BOUISSET, Ch.; DEGRÉMONT, I. y PUYO, J.-Y. Patrimonio y construcción de territorios mediante la imagen: el ejemplo del país de Albret (Francia) y de sus paisajes (siglos XIX y XXI). Estudios Geográficos, 2010, Vol. LXXI, $\mathrm{N}^{\circ} 269$, p. $449-473$.

CARRÉ, J. y METAILIÉ, J. De los paisajes de ayer a los paisajes de mañana. Metodología de un observatorio fotográfico para el análisis de las dinámicas paisajísticas: El valle de Vicdessos, Pirineos de Ariége (Francia). Cuadernos Geográficos, 2008, № 43, p. 123-149.

CARVAJAL, D. y GONZÁLEZ, A. El Papel de los Parques y Museos Mineros en el De- sarrollo Sostenible. Re Metálica Boletín de la SEDPGYM, 2003, № 1, p. 26-36.

COLE, D. Exploring The Sustainability of Mining Heritage Tourism. Journal of Sustainable Tourism, 2004, Vol. 12, № 6, p. 480-494.

FOLCH-SERRA, M. El paisaje como metáfora visual: cultura e identidad en la nación posmoderna. En: NOGUÉ, J. La construcción social del paisaje. Madrid: Biblioteca Nueva, 2007, p. 136-159.

HALL, T. The Robust City. Routledge, 2015.

HASTINGS, J.R. \& TURNER, R.M. The changing mile. Tucson: University of Arizona Press, 1965.

JOHNSON, K.L. Rangeland through time: a photographic study of vegetation change in Wyoming, 1870-1986. Laramie: Agricultural Experiment Station, University of Wyoming (Miscellaneous publications 50), 1987.

KULL, Ch. Historical landscape repeat photography as a tool for land use change research. Norsk Geografisk Tidsskrift-Norwegian Journal of Geography, 2005, Vol. 59, № 4, p. 253-268.

LEPART, J.; DERVIEUX, J. \& DEBUSSCHE, $M$. Photographie diachronique et changement des paysages. Un siècle de dynamique naturelle de la forêt à Saint-Bauzille-de Putois, vallée de I'Hérault. Forêt méditerranéenne, 1996, Vol. XVII, No 2, p. 63-80.

LOCKETT, H.C. Along the Beale Trail: A photographic account of the wasted range lands. Washington: Education division, US Office of Indian Affairs, 1939.

LÓPEZ M.I.; GALDAMES R. y SEGUEL L. Turismo de patrimonio minero y desarrollo local: las percepciones de la comunidad de Lota en Chile. Ciudad y Territorio. Estudios Territoriales, 2010, Vol. XLII, No 164, p. 313-330.

LÓPEZ, M.I. y VIDAL C. Paisaje patrimonial y riesgo ambiental. Reocupación cultural y turística del espacio postminero en Lota, Chile. Revista de Geografía Norte Grande, 2012, No 52, p. 145-165. 
LÓPEZ M.I. y PÉREZ L. Sustentabilidad del turismo en el patrimonio minero: modelo conceptual e indicadores para el ex-territorio carbonífero de Lota y Coronel. EURE, 2013, Vol. 39, No 118, p. 119-230.

LÓPEZ, M.I. y VIDAL C. Efectos de la expansión urbana de Concepción sobre la hidrografía, 1752-2011. En: MÉNDEZ, L. (editor). Geografía y sociedad: el Gran Concepción. Concepción: Ediciones Universidad del Biobío, 2014, p. 349-368.

MATA-PERELLÓ, J.M. (editor). Actas del IV Congreso Internacional sobre patrimonio geológico y minero. VIII Sesión Científica de la SEDPGYM, Aragón Vivo, SL Teruel, 2003.

MAZZEI DE GRAZIA, L. Los británicos y el carbón en Chile. Revista Atenea. Chile: Universidad de Concepción, 1997, № 475, p. 137-167.

MUÑOZ, M.D.; PÉREZ, L.; SANHUEZA, R.; SEGUEL, L. y LÓPEZ, M.I. Identidad, Memoria Colectiva y Participación en el proceso de transformaciones contemporáneas del asentamiento minero de Lota Alto. Concepción: Proyecto FONDECYT No 1040988, Universidad de Concepción y Universidad del Biobío, Archivos CONYCYT, 2006.

MUÑOZ, M.; PÉREZ, L. y SANHUEZA, R. Las ciudades del carbón: Los miradores de Lota Alto, lugares de encuentro social y de comprensión del paisaje. En: GARCÉS, E. (editor). Paisajes culturales, patrimonio y proyecto. Santiago de Chile: Universidad Católica de Chile, 2006, p. 32-39.

ORCHE, E. Puesta en valor del patrimonio minero. Aplicación al caso de las minas de Fontao (Pontevedra). En: CURSO DE VERANO. Defensa del patrimonio geológico y minero., Huelva: Universidad Internacional de Andalucía, 2002a.

ORCHE, E. Parques mineros, desarrollo sostenible y ordenación del territorio. En: Simposio sobre Recursos Mineros y Ordenación del territorio. La Habana: CYTED, Universidad de Moa, 2002b.

ORTEGA, M.L. La Frontera Carbonífera 1840-1900. Mapocho, 1992, № 31, p.131-148.
PALLASMAA, J. Los ojos de la piel. La arquitectura y los sentidos. Barcelona: Editorial Gustavo Gili, 2006.

PÉREZ, L. La mirada y la memoria. Elementos de estructuración y revalorización del paisaje cultural de Lota Alto. Barcelona: Tesis Doctoral, Departament d'Urbanisme i Ordenaciò del Territori, Universitat Politècnica de Catalunya, 2008.

PÉREZ, L. Los Miradores de Lota Alto: Lugares de Encuentro, Comprensión y Revalorización del Paisaje Cultural. Conserva, 2009, No 13, p. 109-122.

PUCHE, O. Patrimonio minero-metalúrgico español: arquitectura y paisajes mineros. En: IV Congreso Internacional sobre Patrimonio Geológico y Minero (defensa del patrimonio y desarrollo regional) y VIII Sesión Científica de la SEDPGYM, 25 y 28 de Septiembre de 2003, Utrillas (Teruel).

PUCHE, O. y MAZADIEGO, L.F. Conservación del Patrimonio Minero Metalúrgico Español: actuaciones y propuestas. Tecnoambiente, 1997, Vol. 69, p. 39-44.

PUCHE, O. \& MAZADIEGO, L.F. Conservation of the European Mining and Metallurgical Heritage - Part 1. CIM Bulletin, 2000, Vol. 93, No 1040, p. 96-107.

SEGUIN, J.F. \& SOUFFLET-LECLERC E. (director). Itinéraires photographiques: Méthode de l'Observatoire photographique du paysage. París: DATAR, 2008.

SHREVE, F. Changes in desert vegetation. Ecology, 1929, Vol. 10, № 4, p. 364-373.

SHREVE, F. \& HINCKLEY, A.L. Thirty Years of Change in Desert Vegetation. Ecology, 1937, Vol. 18, No 4, p. 463-478.

VAN DER VALK, A. Preservation and Development: The Cultural Landscape and Heritage Paradox in the Netherlands. Landscape Research, 2014, Vol. 39, No 2, p. 158-173.

VERGARA, C.J. The New American ghetto. New Jersey: Routledge Rutgers University Press, 1999. 
WEBB, R.H. Grand Canyon, a Century of Change: Rephotography of the 1889-1890 Stanton Expedition. Tucson: University of Arizona Press, 1996.

WOOTEN, E.O. Carrying capacity of grazing ranges in southern Arizona. Bulletin, 1916, No 367. Washington: U.S. Department of Agriculture, 1916.

ZÁRATE, M. Los paisajes culturales urbanos, entre la protección y la destrucción.
Boletín de la Asociación de Geógrafos Españoles, 2011, No 57, p. 175-194.

ZUSMAN, P. Perspectivas críticas del paisaje en la cultura contemporánea. En: Els paisatges de la postmodernitat: II Seminari Internacional sobre Paisatge. 21, 22 y 23 de octubre, 2004, Barcelona, p. 1-7. 